\title{
Effect of Manganese Percentage Doping on Thickness and Conductivity of Zinc Sulphidenanofilms Prepared by Electrodeposition Method
}

\author{
Okafor P. C. ${ }^{1}$, Ekpunobi A. J. ${ }^{2}$, Ekwo P.A ${ }^{3}$ \\ ${ }^{1}$ Department of Physics, College of Education Nsugbe,Anambra State Nigeria \\ ${ }^{2}$ Department of Physics, Nnamdi Azikiwe University, Awka, Anambra State Nigeria
}

\begin{abstract}
Manganese doped zinc sulphidenanofilms were deposited on ITO glass substrates by electrodeposition method using aqueous solution of zinc chloride, manganese chloride, sodium thiosulphate and triethanolamine as a complexing agent triethanolamine. In the present work the effect of manganese percentage doping on thickness and conductivity of zincsulphide were investigated. Structural characterization by X-ray diffraction revealed that Mn doped ZnS:Mnnanofilms have cubic structure with mean crystallite size of approximately $14.19 \mathrm{~nm}$. Optical analysis showed that all films exhibited good transmittance and low absorbance in the visible region. With the increasing of Mn percentage doping, the thickness of the ZnS:Mn films ranged from $46.01-68.99 \mathrm{~nm}$, optical conductivity from 1.20 $\times 10^{13}$ to $2.75 \times 10^{13}$ and electrical conductivity from $1.73 \times 10^{2}$ to $1.51 \times 10^{2}$.Such ZnS:Mn films in nanometer size range with high conductivity could be suitable for applications in the fabrications of thin films solar cells and various optoelectronic devices.
\end{abstract}

Keywords: Effect of manganese percentage doping, Thickness, conductivity, Zinc sulphidenanofilms, Electrodeposition

\section{Introduction}

In recent years considerable interest has been drawn to nanometer sized materials particularly II - VI metal chalcogenide compounds because of the very important role they play in materials research. This kind of nanomaterials exhibits unusual physical and chemical properties in comparison with their bulk materials, such as size dependent variation of the band gap energy and have many potential applications in photochemistry, catalysis and electronic/optical materials $[1 ; 2]$. Furthermore, impurity ions doped into these nanostructures can influence the electronic structure and transition probabilities [3].

Semiconductors with small fractions of cations replaced by magnetic ions are called dilute magnetic semiconductors (DMSs).[4]. Such DMS materials provide unique link between impurity and alloy physics; and a link between magnetism and semiconductivity [4]. As an important II - VI semiconductor material, Zinc suiphide $(\mathrm{ZnS})$ with a wide direct band gap of $3.68 \mathrm{eV}[5]$ is chemically more stable and technogically better than other chalcogenides (such as $\mathrm{ZnSe}$ ), so it is considered to be a promising host material [6]. Doped $\mathrm{ZnS}$ is an important material with an extensive range of applications such asoptical coatings, electro-optic modulator, photoconductors, phosphors, light emitting displays and optical sensors $[1,6,7,8]$. Such doped material has been used widely as an important phosphor for photoluminescence, electroluminescence and cathodoluminescence devices due to its better chemical stability [7].

\section{Literature Review}

Volume 4 Issue 12, December 2015

Paper ID: NOV152475
The properties of thin film materials depend on the method of preparation among other factors which include deposition parameters [9], level of impurity [6,7,10] and annealing process [6,9], level of impurity.Zinc sulphide may exist in form of stable cubic phase at room temperature or in form of hexagonal phase above room temperature or a mixed phase depending on the deposition method, deposition parameters and level of impurity [9]. Many authors had reported the cubic structure for solution growthZnS thin films[1,2,6,9,10,11]. A phase transformation from stableZnS cubic to a hexagonal phase at higher annealing temperatures $\left(\geq 300^{\circ} \mathrm{C}\right)$ had been reported by various authors $[1,8]$.

The thickness of the films increase with the electrolyte concentration and $\mathrm{PH}[12,13,14]$, deposition time [9,15], deposition voltage [9], annealing temperature [16] and dopant ions percentage $[6,7,10]$, The ionic radius $(0,083 \AA)$ of $\mathrm{Mn}^{+2}$ ion is larger than $(0.074 \AA)$ for $\mathrm{Zn}^{+2}$ ion, suggesting that upon doping with slightly large $\mathrm{Mn}$ doping ratio (10\%), the dopant ion enters to the host lattice substitutionary interstitially leading to increasing of the inter-planer spacing (d) values \{17]. The interstitially entrance of the dopant ions lead to expansion of host lattice and particle size increasing [17], an indication of increase in film thickness [9].

The resistivity and conductivity of doped $\mathrm{ZnS}$ thin films are influenced by dopant concentration annealing process and physical factors such as crystal structure, carrier concentration and mobility $[6,18]$. Doping of film samples increases the carrier concentration and enhances the conductivity $[6,10,18]$. Electrical conductivity increase with dopant ions concentration at low doping region but decrease with dopant ions concentration at higher doping region $[6,10,18]$. Decrease in electrical conductivity for heavily doped filmsmay be ascribed 


\section{International Journal of Science and Research (IJSR) \\ ISSN (Online): 2319-7064 \\ Index Copernicus Value (2013): 6.14 | Impact Factor (2014): 5.611}

to theincreasing lattice defects and dislocations of the films $[6,10]$. Decrease in mobility reported for heavily doped film samples may be due to the contribution of scattering mechanism such as ionized impurity scattering [18]. Annealing process improves the crystallinity and increases conductivity of the thin films $[6,16]$, The increase in electrical conductivity for annealed $\mathrm{ZnS}: \mathrm{Mn}$ was attributed to improved $\mathrm{O}_{2}$ vacancies in ZnS:Mn lattice. Different $\mathrm{O}_{2}$ partial pressure controls the metal interstitial and $\mathrm{O}_{2}$ vacancies which leads to crystal defects, an important role for increase in electrical conductivity of $\mathrm{ZnS}$. Zinc sulphide has been reported to have $\mathrm{n}$ - type of conductivity $[6,10]$.

Thin films have been grown by different techniques such as RF magnetron sputtering [19],chemical bath deposition [15], sol gel [20] pulsed laser deposition [21] , spray pyrolysis [10],hydrothermal [8], electrodeposition [9]. Among these techniques, electrodeposition was adopted because of its low cost anddoes not require high temperature and pressure selectivity [9]. Furthermore, this method is scalable with high degree of controllability and reproducibility, hence it is widely applied commercially, [22].

The main purpose of this study is to investigate the effect of manganese percentage doping on the film thickness and conductivity of zinc sulphidenanofilms prepared by electrodeposition method and also to ascertain the possible applications of such DMS nanofilms.

\section{Methodology/ Approach}

Zinc sulphide $(\mathrm{ZnS})$ nanofilms doped with different manganese content were prepared using electrodeposition method using a three electrode cell apparatus.Mn doped $\mathrm{ZnS}$ (ZnS:Mn) nanofilms were prepared by first mixing $10.0 \mathrm{ml}$ of $0.05 \mathrm{M}$ zinc chloride $\left(\mathrm{ZnCl}_{2}\right), 0.05 \mathrm{M}$ manganese chloride $\left(\mathrm{MnCl}_{2} \cdot 2 \mathrm{H}_{2} \mathrm{O}\right)$ and $10.0 \mathrm{ml}$ of $0.05 \mathrm{M}$ triethanolamine (TEA). The concentration of manganese ions were adjusted by controlling the quantity of manganese chloride in the above mixture, varying from $3 \%$ to $23 \%$ (in molar ratio of manganese ions to zinc ions). Then, $10.0 \mathrm{ml}$ of $0.05 \mathrm{M}$ and sodium thiosulphate $\left(\mathrm{Na}_{2} \mathrm{~S}_{2} \mathrm{O}_{3} .5 \mathrm{H}_{2} \mathrm{O}\right)$ were added to the reaction medium and deionized water was added to make the total volume of the solution $50.0 \mathrm{ml}$. The mixture was thoroughly stirred using magnetic stirrer and $\mathrm{PH}$ of the reaction bath was adjusted to constant $\mathrm{PH} 3$ by addition of few drops of hydrochloric acid. The experiment was carried out at room temperature, optimum deposition time (60 seconds) and deposition voltage $(1.0 \mathrm{~V})$ with manganese ions concentration varied from $3 \%$ to $23 \%$. All the reagents used for the electrodeposition were of high analytical grade. Prior to electrodeposition, the ITO glass substrates on which surface the films were deposited were degreased in ethanol for 10 minutes, ultrasonically cleaned for 10 minutes and then dried in a desicator. The deposited ZnS:Mn film samples were rinsed with de-ionized water, dried,annealead at temperature $250^{\circ} \mathrm{C}$ and kept for analysis.
The X-ray diffraction patterns of Mn doped ZnSnanofilms were recorded by X-ray Mini Diffractometer MD 10 Model with a rotating anode and $\mathrm{Cu}-\mathrm{Ka}$ radiation source $(\lambda=0.15406 \mathrm{~nm})$ at $40 \mathrm{KV}$ and $30 \mathrm{~mA}$. Optical transmission data was obtained by JENWAY 6405 UV-Vis spectrophotometer. The thickness and conductivity of the films were determined by optical method"e

\section{Results and Discussion}

The XRD pattern of ZnS:Mnnanofilm sample doped with $8 \%$ $\mathrm{Mn}$ is shown in Fig. 1. The XRD pattern shows that the crystals of $\mathrm{ZnS}: \mathrm{Mn}$ films have cubic structure with preferential orientation along (220) direction and lattice constant $\mathrm{a}=\mathrm{b}=\mathrm{c}=10.045 \AA$. The mean crystallite size calculated using Debye-Scherrer"s formula [23], was estimated to be $14.19 \mathrm{~nm}$. Similar ZnS cubic structure had been reported for nickel (Ni) doped $\mathrm{ZnS}$ [7] and $\mathrm{Mn}, \mathrm{Cu}$ co-doped $\mathrm{ZnS}$ [24].The nanocrystalline nature of the film samples confirmed the nanometer size of their thickness.

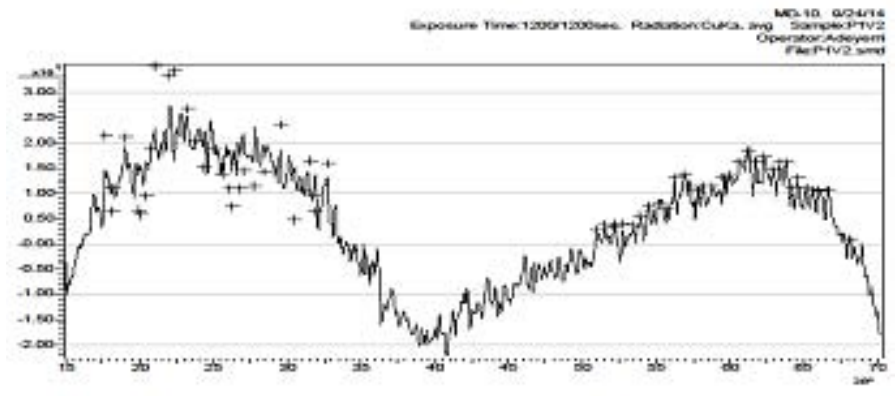

Figure 1: XRD pattern ZnS: Mn film with $8 \%$ Mn doping

The variation of film thickness with manganese percentage doping is shown in Fig.2. The thickness of $\mathrm{ZnS}: \mathrm{Mn}$ films increased from $14.67 \mathrm{~nm}$ to $92.48 \mathrm{~nm}$ as $\mathrm{Mn}$ doing \% increased from $3 \%$ to $8 \%$ and then decreased to $31.80 \mathrm{~nm}$ as Mn doping $\%$ increased to $23 \%$. The highest $(92.48 \mathrm{~nm})$ was obtained from the film sample $\left(\mathrm{P}_{1} \mathrm{C}_{2}\right)$ doped with $8 \% \mathrm{Mn}$. The results showed that at low Mn doping level, the film thickness increased with the increasing of Mn doping \% but decreased with the increasing of Mn doping $\%$ at higher Mn doping level. Similar results had been reported for $\mathrm{Mn}$ doped $\mathrm{ZnS}$ prepared by $\mathrm{CBD}$ [6] and spray pyrolysis [7] respectively.

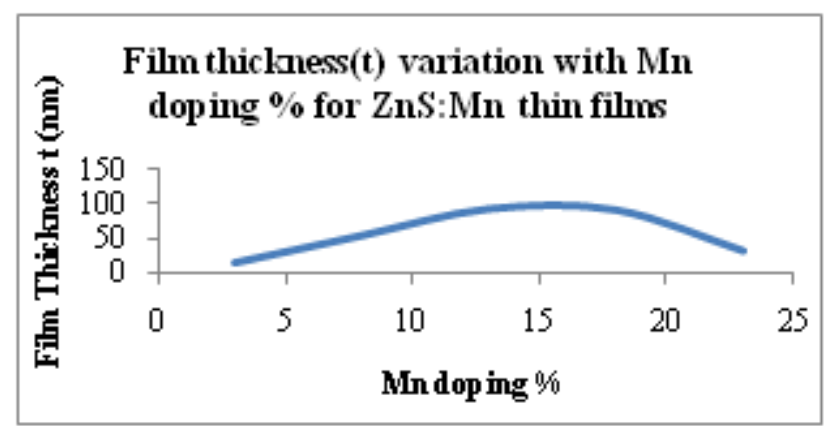

Figure 2: Film thickness variation with Mn doping \% for ZnS:Mn films

Volume 4 Issue 12, December 2015 


\section{International Journal of Science and Research (IJSR) \\ ISSN (Online): 2319-7064 \\ Index Copernicus Value (2013): 6.14 | Impact Factor (2014): 5.611}

Also, decrease in film thickness with the increasing of $\mathrm{Ni}$ doped $\mathrm{ZnS}$ thin films with the increasing of $\mathrm{Ni}^{+2}$ dopant ions concentration had been reported [10]. The film thickness variation with $\mathrm{Mn}^{2+}$ ions concentrations can be explained on the basis of ions concentration in the electrolyte and film formation. When a few percentages of Mn dopant atoms are added into the reaction bath, the electrolyte ions concentration slightly increased thereby resulting to increase in the film growth rate. Because the dopant $\mathrm{Mn}^{2+}$ ions are small, they can easily occupy both the substitutional and interstitial sites of the host lattice. The interstitially entrance of Mn dopant ions with larger ionic radii $(\sim 0.083)$ than that of $\mathrm{Zn}(\sim 0.074)$ leads to expansion of the host lattice and hence particle size increasing as well as increase in the film thickness. At higher $\mathrm{Mn}^{2+}$ ions concentrations, more ions are presence in the electrolyte and this results to decrease in the mobility and reduction in the growth rate thereby leading to decrease in the grain size, an antecedent to decrease in the film thickness.Based on the results obtained, we, therefore, conclude thatMn doping \% has strong effect on the thickness of $\mathrm{ZnS}: \mathrm{Mn}$ films andelectrodeposition using $13 \% \mathrm{Mn}$ doping at room temperature was the best condition for the preparation of good quality of suchnanofilms at the current condition. Such ZnS:Mnnanofilms are good candidate materials for applications in various fields of nanofilms technology such as nanofilms solar cells and various optoelectronic devices $[6,9.10]$.

The absorption, optical and electrical conductivity spectra of Mn doped $\mathrm{ZnS}$ are respectively shown in Fig.3,4 and 5

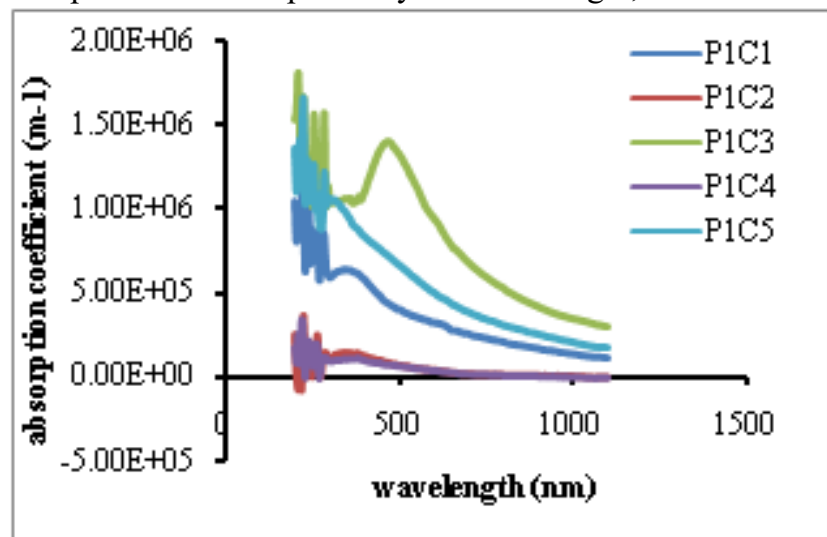

Figure 3: Absorption Spectra of $\mathrm{ZnS}: \mathrm{Mn}$ films with different Mn doping \%

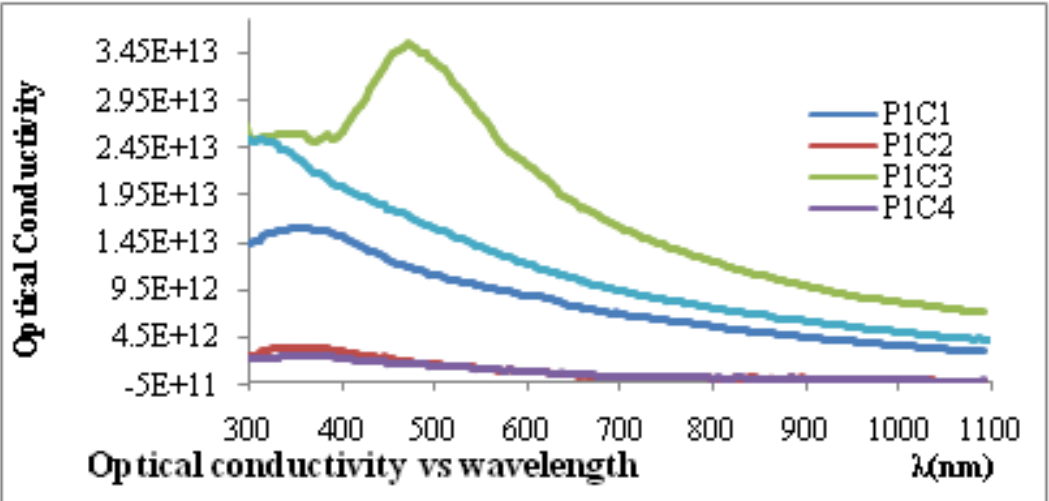

Figure 4: Optical conductivity spectra of ZnS:Mn films with different Mn doping\%

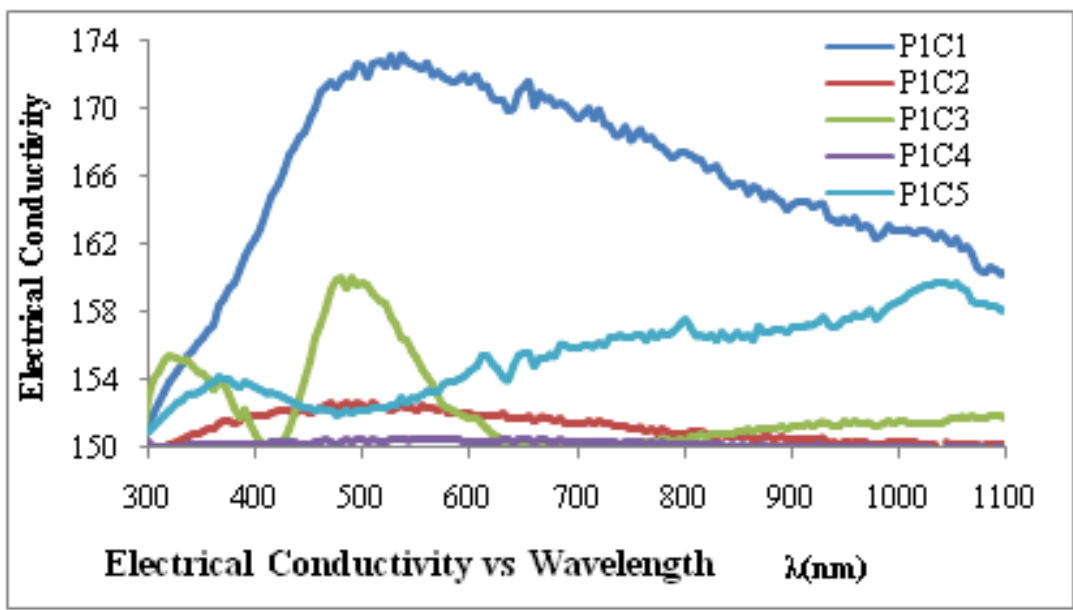

Figure 5: Electrical conductivity spectra of ZnS:Mn films with different Mn doping\%

Fig 3 revealed that the absorption coefficient $(\alpha)$ Vis and low in the NIR region. At wavelength of 550nm in the ofZnS:Mnnanofilm samples were relatively high in the UV- visible region, the average absorption coefficient of the 


\section{International Journal of Science and Research (IJSR) \\ ISSN (Online): 2319-7064 \\ Index Copernicus Value (2013): 6.14 | Impact Factor (2014): 5.611}

ZnS:Mn films decreased from $0.40 \times 10^{6}$ to $0.10 \times 10^{6}$ as $\mathrm{Mn}$ doping $\%$ increased from $3 \%$ to $8 \%$ and then increased to 1.20 $\mathrm{x} 10^{6}$ with further increase in Mndoping \%.The highest absorption coefficient was obtained from the film sample $\left(\mathrm{P}_{1} \mathrm{C}_{3}\right)$ doped with $13 \% \mathrm{Mn}$. The observed difference in the absorption coefficient peak values of the $\mathrm{ZnS}$ : Mn films indicates that Mn doping \% has strong effect on the absorption coefficient of the film samples. The obtained absorption coefficient values of magnitude $10^{6}$ compare well with $10^{6}$ reported for undoped $\mathrm{ZnS}$ deposited in alkaline medium at $\mathrm{PH}$ 9-11 [14]. The obtained absorption coefficient of magnitude $10^{6}$ are within the range of $10^{6}$ to $10^{-7}$ required for semiconductor thin film solar cells. Such films with high absorption coefficient in the visible region are good candidate materials for optical coatings, thin films solar cells fabrications, optoelectronic and electroluminescent devices applications.

The optical conductivity $\sigma_{0}$ spectra of $\mathrm{ZnS}$ :Mnnano films with different Mn percentage doping shown in Fig 4 revealed that the optical conductivity of the $\mathrm{ZnS}$ :Mnnanofilms samples are relatively high in UV-Vis regions and low in NIR region with its value varying from $3.55 \times 10^{13}$ to $1.0 \times 10^{13}$ with the increasing of wavelength from $300 \mathrm{~nm}$ to $1100 \mathrm{~nm}$. At wavelength of $550 \mathrm{~nm}$ in the visible region, the average optical conductivity of $\mathrm{ZnS}: \mathrm{Mn}$ films increased from $1.25 \times 10^{13}$ to $2.75 \times 10^{13}$ as Mn doping \% increased from 3\% to $13 \%$ and then decreased to $0.12 \times 10^{13}$ with further increase in $\mathrm{Mn}$ doping \%.The difference in the peak values of optical conductivity of $\mathrm{ZnS}: \mathrm{Mn}$ film samples indicates that Mn doping $\%$ has significant effect on the optical conductivity of the film samples. The obtained results compare well with the average optical conductivity of magnitude $10^{13}$ to $10^{12}$ reported by for undopedZnS [14]. The high optical conductivity of magnitude $10^{13}$ of the deposited $\mathrm{ZnS}: \mathrm{Mn}$ films indicates that they have good photo response and could be employed as photoconductors [1]. Such films are good candidate materials for thin film solar cells fabrication and various optoelectronic devices applications.[1,6,7,10].

The electrical conductivity $\left(\sigma_{\mathrm{e}}\right)$ spectra of ZnSnanofilms doped with different $\mathrm{Mn}$ doping \% shown in Fig.5 revealed that electrical conductivity $\left(\sigma_{\mathrm{e}}\right)$ of all the $\mathrm{ZnS}$ :Mnnanofilms were high in the wavelength range of $350 \mathrm{~nm}$ and $800 \mathrm{~nm}$ with its value varying from $1.72 \times 10^{2}$. to $1.50 \times 10^{2}$ as wavelength increased from $300 \mathrm{~nm}$ to $1100 \mathrm{~nm}$. At wavelength of $550 \mathrm{~nm}$ in the visible region, the average electrical conductivy of ZnS:Mnnanofilms decreased from $1.73 \times 10^{2}$ to $1.53 \times 10^{2}$ as Mn doping \% increased from 3\% to $8 \%$ and then increased to $1.56 \times 10^{2}$ with further increase in Mn doping \% with the exception of the film sample doped with $18 \% \mathrm{Mn}$ which exhibited the lowest average electrical conductivity of $1.51 \mathrm{x}$ $10^{2}$. The average electrical conductivity of magnitude $10^{2}$ obtained for the film samples falls within the electrical conductivity range of $10^{-13}$ to $10^{2}$ for reported semiconductor. The decrease in electrical conductivity may be attributed to the surface tension due to substitution of $\mathrm{Zn}^{2+}$ with $\mathrm{Mn}^{2+}$ causing electro neutral effects [10] andcould also be ascribed to increasing of lattice defects and dislocations of the films $[6,10]$.

\section{Conclusion}

Manganese doped ZnSnanofilms with differentMn percentage doping have been successfully deposited on ITO glass substrates by electrodeposition method. The XRD studies revealed that $\mathrm{ZnS}$ :Mnnanofilms have cubic structure with crystallite size of approximately $14.19 \mathrm{~nm}$. The optical analysis showed that all the films had high transmittance in the visible region. With the increase of $\mathrm{Mn}$ percentage doping, the thickness of the ZnS:Mnnanofilms ranged from $46.01 \mathrm{~nm}$ to $68.99 \mathrm{~nm}$, optical conductivity from $0.20 \times 10^{13}$ to $1.63 \times 10^{13}$ and electrical conductivity from $1.520 \times 10^{2}$ to $1.63 \times 10^{2}$. The results revealed that the the thickness and conductivity of ZnS:Mnnanofilm were dependent on Mn percentage doping. Such ZnS:Mn thin films with thickness in nanometer size range and high conductivity are promising candidate materials for thin films solar cells fabrications and various optoelectronic devices applications. We recommend that other research work should be carried out on CdSnanofilms codoped with $\mathrm{Mn}$ and any other transition metal using the same deposition conditions.

\section{Acknowledgement}

The authors are thankful to Crystal Growth \& Characterization Laboratory, Solid State \& Materials Science Division, University of Nigeria, Nsukka for providing the laboratory facilities for the growth of the film samples and Engineering Materials Development Institute, Akure-Nigeria for extending $\mathrm{X}$-ray diffraction and UV-Vis Spectrophotometer facilities for the present work.

\section{References}

[1] Khalid T. Al-Rasoul, Nada K. Abbas, Zainb J. Shanan (2013); ,Structural and Optical Characterization of $\mathrm{Cu}$ and Ni-doped ZnS nanoparticles ${ }^{\text {ee }}$ Int. J. Electrochem. Sci. 8 (2013), 5594-5604

[2] Dang Q; Genwang W; Christopher M; and Kenneth J.K (2009). „Cadmium (Zinc) manganese sulphidenanocrystalline $\left(\mathrm{Cd}_{1-\mathrm{x}} \mathrm{Mn}_{\mathrm{x}} \mathrm{S}\right.$ and $\left.\mathrm{Zn}_{1-\mathrm{x}} \mathrm{Mn}_{\mathrm{x}} \mathrm{S}\right)$ dilute magnetic semiconductors: Synthesis, annealing and effects of surface oxidation on magnetic propertiese, Arabian Journal of Chemistry, 41:63-68

[3] Peng W.O; Cong G.W; QuS . C; and Wang Z.G; (2006); ,Synthesis and Photoluminescence of $\mathrm{ZnS}: \mathrm{Cu}$ nanoparticles Optical materials, 29 (2-3), 313 -317

[4] Zahari Z; (2005). „Magnetic Properties of Semi magnetic semiconductor materials $\mathrm{A}^{\mathrm{II}} \mathrm{B}^{\mathrm{VI}}$ type ${ }^{\text {ee }}$ Annuari de L'Universite, St. KlimentOhridski, Faculte de Physique, $98(5), 21$

[5] Saravanan N; The G. B; Yap S.Y.P and Cheong K.M;(2008); "Simple Synthesis of ZnS nanoparticles in alkaline medium", Journal of Materials Science. Materials in Electronics, 19 (12) $1206-1208$

Volume 4 Issue 12, December 2015 


\section{International Journal of Science and Research (IJSR) \\ ISSN (Online): 2319-7064}

Index Copernicus Value (2013): 6.14 | Impact Factor (2014): 5.611

[6] Gode F. and Gumus (2009); Influence of Copper and Manganese concentrations on the properties of polycrystalline ZnS:Mn thinfilms"; Journal of Optoelectronics and Advanced materials, 11(4), 426-436

[7] Pathak, C.S; Pathak, P.K; Kumar P; Mandal M.K; (2012), "Characterization and Optical properties of $\mathrm{Ni}^{2+}$ doped ZnS nanoparticles"; Journal of Ovonic Research, 8(1), 1520

[8] Rashad, M.M; Rayan D.A; El-Barawy K; (2009), "Hydrothermal Synthesis and Magnetic properties of Mn doped ZnS nanoparticles", International Conference on Magnetism (ICM, 2009), Journal of Physics Conference Series 200 (7): 072077

[9] Anuar K; Saravanan N; Ho S.M; Noraini K; (2010); "XRD AFM studies of $\mathrm{ZnS}$ thin films produced by electrodeposition", Arabian Journal of Chemistry, 3 (4), 243-249

[10] Ozutok F; Erturk K; and Bilgin V; (2012);"Growth, Electrical and Optical study of ZnS:Mn thin films", ACTA Physical Polonica A, 121 (1), 221-223

[11] Oznuluer T. Erdolan I; and Dernir U; (2006); "Electrochemically induced atom-by atom growth of $\mathrm{ZnS}$ Co deposition"; Langmuir 22 (9), 4415

[12] Anuar K; Saravanan N; Tan W.T Khor L.K and Ho S.M (2010); "Effect of PH and electrolyte concentration on the copper sulphide thin films prepared by chemical bath deposition method", Journal of Science, 23 (4), 435-443

[13] Ezema F.I, and Nwankwo U.O.A; (2011), "Effect of Concentration of Mn dopant on the structural and optical properties of Zinc Oxide crystals", Biostructures; 6(1), 273-280

[14] Ilenikhena P.A. (2008); “Comparative studies of improved chemical bath deposited copper sulphide $(\mathrm{CuS})$ and Zinc Sulphide (ZnS) thin films at $320 \mathrm{~K}$ and possible application", Afrrican Physical Review, 2(7), 59-67

[15]Ladar, M; Popovici E. J; Baldealon, G.R; and Indrea E; (2007); "Studies on Chemical bath deposited Zinc Sulphide (ZnS) films with special Optical properties"; Journal of Alloys and Compounds; 432-435, 697-700

[16] Ezema F.I, Ezeugwu S.C; Osuji, R.U; Asogwa P.U; Ezeokoye B.A; Ekwealor A.B.C and Ogbu M.P; (2010); "The role of thermally annealing on the optical and solid state properties of chemically deposited CdSnanocrystalline thin films grown in a polymer matrix"; Journal of Non-Oxide Glasses, 1(1), 45-50

[17] Saeed S.E; Abdel-Mottaleb M.M.S; and Abdel-Mottaleb MSA; (2014). "One step thermolysis synthesis of divalent transition metal ions monodoped and tridopedCdS and $\mathrm{ZnS}$ luminescent nanomaterials"; Journal of Nanomaterials, (2014), Article ID 873036, 11 pages

[18] Al-shammari A.S; MullaAmanullah F.M and Al-Dhafiri A.M; (2005); "Preparation and Characterization of Chlorine doped CdS thin films and their applications"; M.Sc Thesis, Department of Physics, King Saud University, College of Science. Department of Physics. Riyadh. Saudi Arabia.

[19] Ghafouri V; Shariatl M; Ebrahinzal A; (2012); "Pholuminescence investigation of Crystalline
undopedZnO nanostructures on structured by RF sputtering"; Sci. Iran Trans F 19 (3), 934-942

[20]Ezema F.I; and Nwankwo, U.O.A; (2011), "Effect of Concentration of $\mathrm{Mn}$ dopant ions on the structural and optical properties of zinc oxide crystals"; Biostructures, 6(1), 273-280

[21] Kentaro, S; Kohei, N; Atsuhiko, F; Tetsuo, I; and Tatsuo O; (2009); "Low temperature photoluminescence of nanostructuralZnO crystals synthesized by pulsed-laser Ablation"; Jpn. J. Appl. Phys. 48, 085001

[22] Kadirgan F; Mao D; Song W; Ohno T; McCandless B; (2000); "Properties of electrodeposited CdS films for photovoltaic device with comparison to $\mathrm{CdS}$ prepared other methods"; Turk. J. Chem. 24, 21-33

[23] Cullity B.D; (1991); "Elements of X-ray diffraction", $3^{\text {rd }}$ Ed.; Prentice - Hall Englewood Cliffs N.J. 2001Y

Volume 4 Issue 12, December 2015 